\title{
Modern methods of managing innovative processes at enterprises of the real sector of the economy
}

\author{
Sofya Diakonova ${ }^{1, *}$ and Elena Nidziy ${ }^{2}$ \\ ${ }^{1}$ Voronezh State Technical University, Moscow Avenue, 14, Voronezh, 394026, Russia \\ ${ }^{2}$ Moscow State University of Civil Engineering, Yaroslavskoe sh., 26, Moscow, 129337, Russia
}

\begin{abstract}
The purpose of this study is to develop modern methods for managing innovative processes at enterprises of the real sector of the economy. The structure of the concept of innovative innovation management from the position of fundamental and marketing approaches has been developed. To implement the concept, it is important to be able to manage innovations using the protective, strategic functions of the created innovations that provide technological and informational advantages and block the entry of competitors into the market. Based on the analysis of the group features of innovations, two groups of classifications were developed, depending on the goals of creating innovations and the resources used. The developed model for the development of innovative processes allows enterprises to improve innovative processes for more efficient production and sales of products.
\end{abstract}

\section{Introduction}

Innovations are distinguished on the basis of content or internal structure on technical, economic, organizational, managerial, etc. There are such features as the scale of innovation (global and local); life cycle parameters (stages, substages, phases), implementation patterns, etc. [1].

Innovations are different and multifaceted in nature, so there are many classifications of innovations, developed both in foreign countries and by domestic scientists. The grouping of innovations according to certain characteristics and features is called the classification of innovations.

The most significant success factors of an enterprise on the market can be identified:

1) superiority of the product over its competitors (the presence of its distinctive properties that contribute to a better perception of it by the consumer);

2) effective innovative marketing, for example, a better market study, an understanding of customer behavior, variation in the product life cycle, etc.;

3) high synergy of R\&D and production, i.e. availability of technological advantages.

Studies of the levels of product success measured by one of these factors are 82, 79 and $64 \%$, respectively, and $90 \%$ for all three factors [2].

\footnotetext{
*Corresponding author: sof1355@yandex.ru
} 
Based on the indicated factors that give significant advantages to industrial enterprises over competitors, we emphasize two conceptual positions:

1. Fundamental, i.e. based on scientific research and providing the product with distinctive technical and technological properties.

2. Marketing, i.e. based on the study of market and consumer needs.

\section{Materials and Methods}

The concept of this study is based on the assumption that in order to increase investment and innovation attractiveness, enterprises need to manage intellectual products from the standpoint of fundamental and marketing approaches [3].

For a full assessment (from the standpoint of the concept) of innovation, it is necessary to implement several successive stages:

1. Classification of innovation.

2. Model of development of innovation processes, including the diffusion of innovation.

3. Implementation of innovation as intangible assets at the enterprise.

This algorithm is illustrated in Fig. 1.



Fig. 1. Concept structure.

The success of innovations brought to the market by producers is determined by the degree of diffusion that takes place, its scale. Therefore, it is precisely diffusion that is set as a goal when solving the problems of achieving success of innovation processes [4]. 
Diffusion of innovations is the process of spreading an innovation that has already been mastered once in new conditions. This process is a predictable pattern and occurs under the influence of certain factors (author).

In the process of studying diffusion, it was found that there are certain patterns that include the innovation itself, the transfer of information from one subject to another in terms of a community or social environment, and all these components are subject to a temporary factor [4-12].

\section{Results}



Fig. 2. Classification of innovations by the nature of occurrence. 


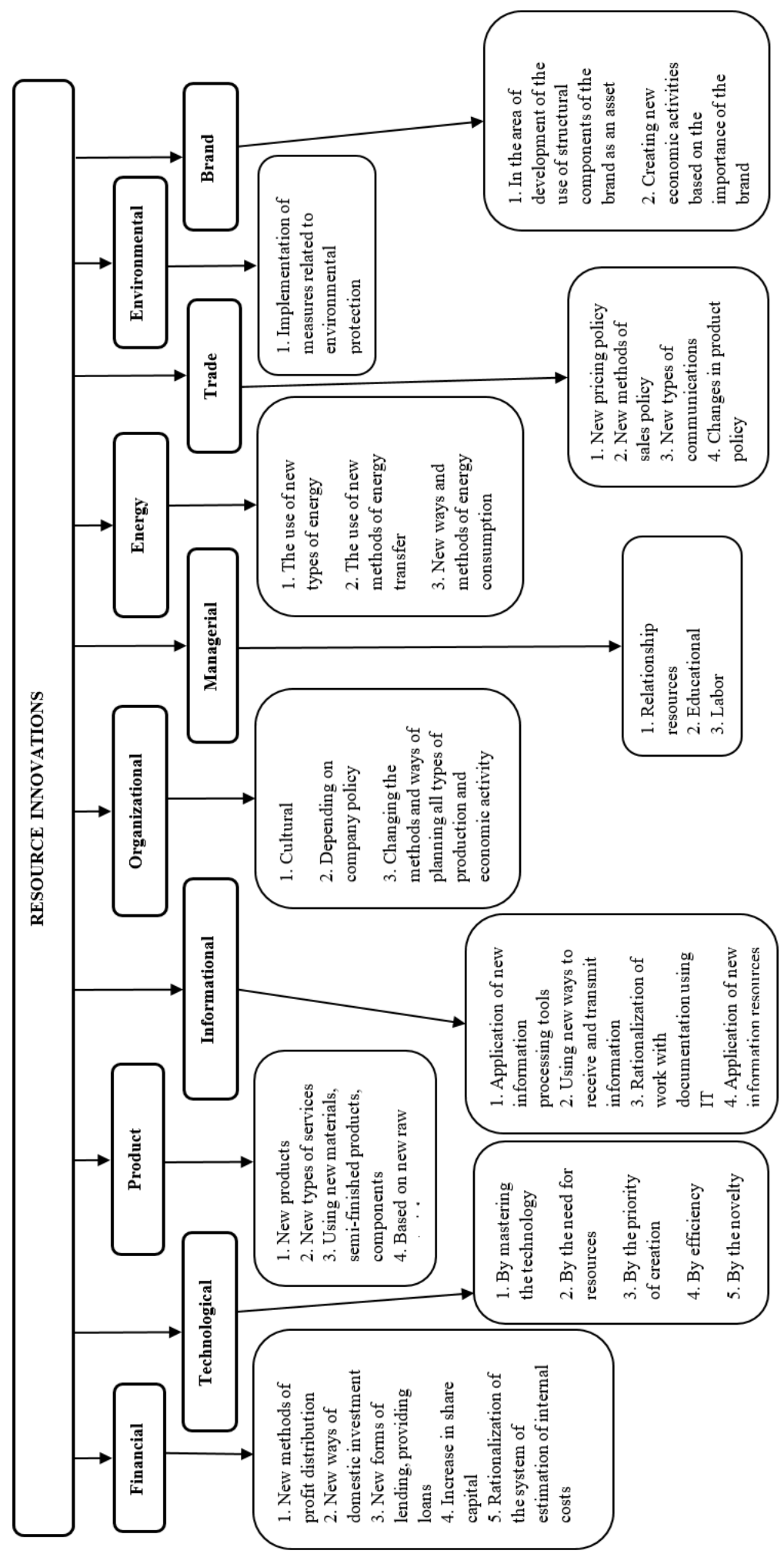

Fig. 3. Resource classification of innovations. 
We have analyzed the most well-known classifications of innovations and technologies both in domestic and in foreign literature, on the basis of which we formulated our own decision in the area of innovation classification.

It is possible to align the classification according to two signs, so the following classification options are proposed in the paper:

1) depending on the purpose of occurrence;

2) depending on produced and consumed resources.

By the nature of occurrence (Fig. 2), innovations can be divided into:

1. targeted, i.e. the creation of innovations occurs as a result of a project depending on specific goals;

2. secondary, i.e. obtained in parallel with the targeted ones;

3. arising in the course of civilization development: spontaneous, occasional and selfdeveloping.

Depending on the goals that lead to the occurrence of a particular innovation, it is possible to divide them into:

- innovations of a fundamental nature, i.e. the cause of their occurrence is scientific research; the appearance of such innovations is caused by the development of science and technology and the development of production;

- marketing innovations, i.e. the reason for their occurrence is the market needs - already existing ones, manifested in the future, caused by strategic and competitive reasons, and also blocking ones (preventing penetration and capturing of the market by other enterprises).

Fig. 3 shows the classification in terms of produced and consumed resources, as well as from the standpoint of resource coverage by enterprises. Ten groups of resources are represented $[5,6]$.

It should be noted that some innovations overlap with each other in the classification, i.e. applicable by a number of properties in several classification groups. Nevertheless, according to the specific classification criteria considered, the fullest characteristic is given.

\section{Discussions}

Spreading of innovations, as well as their creation, is an integral part of the innovation process. Innovation process is the set of scientific, technical, technological and organizational changes that occur during the implementation of innovations.

Creation of innovations and their subsequent use in enterprises directly depends on the goals pursued by the producer. But it is also important to be able to dispose of innovations, using the protective, strategic functions of the created innovations that give technological and informational advantages, block the entry of competitors to the market, and anticipate the emergence of analogues from competitors.

\section{Conclusion}

As a result of the analysis of the most well-known classifications of innovations and technologies both in the domestic and foreign literature, it was revealed that there is no such criterion as the goal of creating innovation. This gap in the theory of innovation is filled by the authors of the publication.

The "resource" classification of innovations is completely new and poorly studied. While developing the classification, the authors covered a very broad scope of technical and economic and financial development of human activity. 
Studies of classification of innovations have a conceptual relationship with the developed model of development of innovative processes, which allows enterprises to improve innovation processes for the development and sale of their products.

\section{References}

1. S.V. Domnina, E.V. Savoskina, N.V. Shekhova, Procedia Engineering 153, 741-746 (2016)

2. T. Simankina, M. Romanovich, O. Tsvetkov, MATEC Web of Conferences 53, 01054 (2016)

3. L. Ustinovicius, R. Rasiulis, L. Nazarko, T. Vilutienè, M. Reizgevicius, Procedia Engineering 122,166-171 (2015)

4. P.G. Grabovy, A.K. Orlov, Procedia Engineering 153, 195-202 (2016)

5. E.K. Chirkunova, E.E. Kireeva, A.D. Kornilova, J.S. Pschenichnikova, Procedia Engineering 153, 112-117 (2016)

6. N. Safronova, E. Nezhnikova, A. Kolhidov, MATEC Web of Conferences 106, 08024 (2017) doi:10.1051/matecconf/201710608024

7. O. Pirogova, M. Makarevich, O. Ilina, V. Ulanov. Proceedings: IOP Conference Series: Materials Science and Engineering. P. 012129. (2019) DOI: 10.1088/1757899X/497/1/012129

8. I. Ilin, O. Voronova, T. Knykina. Proceedings of the 33rd International Business Information Management Association Conference, IBIMA 2019: Education Excellence and Innovation Management through Vision 2020. P. 5112-5121. (2019)

9. T. Lebedeva, A. Yakovlev, N. Kepp, R. Ikramov. Proceedings: IOP Conference Series: Materials Science and Engineering, 497, 012132. (2019) DOI: 10.1088/1757$899 \mathrm{X} / 497 / 1 / 012132$

10. O. Kalinina, E. Balchik, S. Barykin. Proceedings: MATEC Web of Conferences. 239. P. 04021. (2018) DOI: 10.1051/matecconf/201823904021

11. A. Bril, O. Kalinina, A. Levina. Proceedings: E3S Web of Conferences. 33. P. 03004 (2018) DOI: 10.1051/e3sconf/20183303004

12. O. Kalinina, S. Firova, S. Barykin, I. Kapustina. Advances in Intelligent Systems and Computing. 982. P. 318-324. (2020) DOI: 10.1007/978-3-030-19756-8_29 